\title{
A refrigeração no diagnóstico de Salmonella spp. utilizando o método microbiológico tradi- cional e reação em cadeia da polimerase em carcaças de frango
}

\author{
The cooling on the diagnostic of Salmonella spp. using traditional microbiologic method and the \\ polymerase chain reaction in poultry carcasses
}

\author{
Fabio Sossai Possebon ${ }^{\mathrm{I}}$ Luis Felipe Zuccolo Paschoal da Costa ${ }^{\mathrm{I}}$ Ricardo Seiti Yamatogi ${ }^{\mathrm{II}}{ }^{*}$

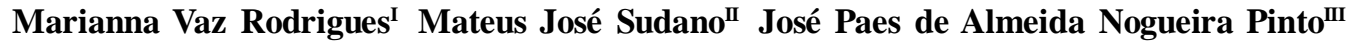

\section{RESUMO}

A pesquisa de Salmonella em carcaças de aves tem mostrado resultados discrepantes, dependendo se as amostras foram colhidas ainda na indústria, imediatamente após o chiller ou no comércio varejista, quando se encontram submetidas à refrigeração por vários dias. Técnicas mais sensíveis, tais como a Reação em Cadeia pela Polimerase $(P C R)$, podem fornecer dados importantes sobre o efeito do resfriamento sobre as células do patógeno, comparando seus resultados com os da metodologia microbiológica convencional (MC). Foram colhidas 130 carcaças de frango, sendo que 65 foram obtidas ainda na indústria (pós-chiller) e imediatamente analisadas e 65 carcaças embaladas e estocadas a $5^{\circ} \mathrm{C}$ por 72 horas (simulando o varejo), sendo então realizada a pesquisa do patógeno por ambas as técnicas. Do total analisado (130 amostras), a PCR foi capaz de detectar 58 positivas $(44,6 \%) e$ a MC 50 (38,5\%). Ambas as técnicas detectaram um número superior de amostras positivas para Salmonella em carcaças colhidas ainda na indústria, quando comparadas às do varejo. A PCR detectou $50,77 \%$ de positividade em amostras da indústria e $38,46 \%$ em amostras do varejo. Para a MC, esses valores foram de 46,15\% (indústria) e 30,77\% (varejo). Concluímos que o resfriamento das carcaças a $5^{\circ} \mathrm{C}$ por 72 horas pode ser um fator limitante na detecção de Salmonella quando a pesquisa do patógeno se faz pela metodologia microbiológica convencional.

Palavras-chave: Salmonella, frango, PCR, refrigeração.

\section{ABSTRACT}

The survey of Salmonella in poultry carcasses has shown conflicting results, depending on whether the samples were taken yet in the factory, immediately after the chiller or retail market, when they are subjected to refrigeration for several days. More sensitive techniques such as Polymerase Chain Reaction (PCR) can provide important data on the effect of cooling on the cells of the pathogen by comparing their results with those of conventional microbiological methods (CM). It was collected 130 chicken carcasses, wich 65 were obtained yet in the industry (post-chiller) and immediately analyzed and 65 carcasses packaged and stored at $5^{\circ} \mathrm{C}$ for 72 hours (simulating retail), and then research of the pathogen was performed by both techniques. Of the analyzed total (130 samples), PCR was able to detect 58 positive (44.6\%) and CM, 50 (38.5\%). Both techniques detected a higher number of samples positive for Salmonella on carcasses collected yet in the factory when compared to those of retail. The PCR detected $50.77 \%$ of positive industry samples and $38.46 \%$ of retail samples. CM for these values was $46.15 \%$ (factory) and $30.77 \%$ (retail). We conclude that the cooling of the carcasses for at $5^{\circ} \mathrm{C}$ for 72 hours can be a limiting factor in the detection of Salmonella when the pathogen research is done by conventional microbiological methods.

Key words: Salmonella, poultry, PCR, refrigeration

As Doenças Transmitidas por Alimentos (DTA) constituem uma grande preocupação à saúde pública e, entre as bactérias, Salmonella é um das mais frequentes, causando milhões de casos, hospitalizações e mortes (MEAD et al., 1999). Os produtos avícolas constituem um dos principais alimentos relacionados a este patógeno e sabe-se que uma porcentagem variável das carcaças de frango

IFaculdade de Medicina Veterinária e Zootecnia (FMVZ), Universidade Estadual Paulista (UNESP), Campus Botucatu, Botucatu, SP, Brasil.

"Departamento de Reprodução Animal e Radiologia Veterinária, FMVZ, UNESP, Campus Botucatu, Botucatu, SP, Brasil.

"'Departamento de Higiene Veterinária e Saúde Pública, FMVZ, UNESP, Campus Botucatu, Distrito de Rubião Junior, s/n, CP 572, 18618-970, Botucatu, SP, Brasil. E-mail: rsyvet@yahoo.com.br. *Autor para correspondência. 
encontra-se contaminada, resultando em produtos positivos para Salmonella spp. no comércio varejista, os quais podem dar origem a casos e/ou surtos de salmonelose humana (NZFSA, 2007).

Preocupados com esta questão, vários países têm desenvolvido Programas de Redução (PRP) deste micro-organismo. No Brasil, o Programa foi instituído pela Instrução Normativa no 70, de 06 de outubro de 2003 (BRASIL, 2003).

A despeito da introdução do PRP brasileiro em 2003, a literatura continua registrando a detecção de Salmonella num elevado número de carcaças no comércio varejista (CARVALHO \& CORTEZ, 2008). Tal situação não é exclusiva do Brasil, já que índices elevados de contaminação têm sido também observados em outros países que também implementaram programas semelhantes de redução do patógeno em carcaças de frango (SIMMONS et al., 2003; FLETCHER, 2006).

Para a detecção do agente nas carcaças, os programas preconizam o emprego de métodos microbiológicos convencionais (MC), que, além de dispendiosos, podem levar até sete dias para a obtenção do resultado (FRESCHI et al., 2005). Já os métodos rápidos, como a Reação em Cadeia pela Polimerase (PCR), podem produzir respostas em poucas horas, além de serem altamente sensíveis e específicos. Atualmente, podem ser uma poderosa ferramenta para as análises microbiológicas (PERSING, 1991).

Nesse sentido, tais atributos podem ser bastante úteis na investigação do patógeno em carcaças colhidas não somente na indústria, mas também no varejo, visto que a metodologia microbiológica convencional apresenta problemas na detecção do agente. $\mathrm{Na}$ indústria, vários tratamentos efetuados durante o abate, tais como o emprego de enxágues sucessivos de toda a carcaça com água clorada, utilização de agentes antimicrobianos e a presença de cloro residual nas amostras, tornam difícil essa detecção (FLETCHER, 2006). Já no varejo, a exposição ao frio durante a comercialização do produto poderia diminuir o número de células do agente, bem como torná-las inviáveis e não detectáveis em nove dias, conforme relatam JIMENEZ et al. (2009).

Para a realização deste trabalho, coletou-se em 2009 um total de 130 carcaças originárias de um mesmo lote de produção a cada dia de coleta, realizada em um abatedouro de aves localizado na região de Botucatu, SP, mantido sob Inspeção Federal. As carcaças foram divididas em dois grupos: 65 delas colhidas na indústria após o chiller (resfriamento) e 65 delas colhidas após a sua embalagem. Todas as amostras foram identificadas e imediatamente transportadas em caixas plásticas isotérmicas contendo gelo reciclável para o Laboratório de Pesquisas FMVZ/UNESP/Botucatu. As 65 amostras colhidas após o chiller foram analisadas dentro de um prazo máximo de duas horas. As embaladas na indústria foram estocadas a $5^{\circ} \mathrm{C}$ por 72 horas em estufas B.O.D., ( sendo então submetidas à pesquisa de Salmonella spp.

Foram retirados $25 \mathrm{~g}$ de pele de cada carcaça, conforme preconizado por BRASIL (2003), sendo então adicionados $225 \mathrm{~mL}$ de Água Peptonada Tamponada a $1 \%$, realizando-se a homogeneização da mistura por 3 minutos em stomacher. O isolamento de Salmonella foi realizado conforme ANDREWS et al. (1998), após enriquecimento da amostra em caldo RappaportVassiliadis e caldo Tetrationato, isolamento em placas contendo Xilose-lisina-desoxicolato, Sulfito-Bismuto e Manitol Lisina Cristal Violeta Verde Brilhante. As colônias suspeitas foram repicadas para tubos contendo Agar Tríplice Açúcar Ferro - TSI e Agar Lisina Ferro - LIA e, dos tubos com reação característica para o patógeno, foram realizadas provas bioquímicas complementares (indol, Voges Proskauer, vermelho de metila, citrato, uréia, fenilalanina e movimento) e prova de sorologia com anti-soro polivalente $\mathrm{O}$ e $\mathrm{H}$.

Paralelamente, para o diagnóstico molecular, $1 \mathrm{~mL}$ de cada um dos caldos de enriquecimento foi centrifugado a $10.000 \mathrm{~g} 10 \mathrm{~min}^{-1}$. O sobrenadante foi desprezado e o sedimento ressuspendido em $1 \mathrm{~mL}$ de solução tampão de fosfato 0,01M, pH 7,2 - PBS. Esta etapa foi repetida mais duas vezes, com tempo de centrifugação de 5 minutos. $O$ protocolo de extração foi realizado conforme ARNOLD et al. (2004).

Para as reações de PCR, utilizou-se um volume total de $25 \mu \mathrm{L}$, composto por $2,5 \mu \mathrm{L}$ de tampão de PCR 10x concentrado, $0,75 \mu \mathrm{M}$ de Cloreto de Magnésio, 200 $\mu \mathrm{M}$ de cada dNTP, $1 \mathrm{U}$ de Taq DNA Polimerase, 10 picomoles de cada iniciador, água ultrapura autoclavada (qsp) e $3 \mu \mathrm{L}$ da amostra de DNA. A incubação foi realizada em termociclador PTC-100 (MJ Research, Inc.), empregando-se os parâmetros de $94^{\circ} \mathrm{C} / 5$ minutos para desnaturação inicial, seguidos por 35 ciclos com $94^{\circ} \mathrm{C} / 30 \mathrm{~s}, 60^{\circ} \mathrm{C} / 30$ s e $72^{\circ} \mathrm{C} / 30$ s. A extensão final foi realizada a $72^{\circ} \mathrm{C} / 4$ minutos. Em todas as reações realizadas, foi utilizado um controle negativo, através da substituição da amostra por água ultrapura, um controle positivo com uma cepa padrão de Salmonella Enteritidis ATCC 13076 e um controle interno de 371pb (16S rRNA) realizadocom auxílio de iniciadores (primers) universais segundo GREISEN et al. (1994). A amplificação do controle interno confirmou o bom desempenho da PCR e que não havia agentes inibitórios 
na reação e extração. Os iniciadores (primers) utilizados na pesquisa do patógeno codificavam para o gene invA, gerando um fragmento de $284 \mathrm{pb}$, conforme RAHN et al. (1992). Os produtos das reações de PCR foram submetidos à eletroforese em gel de agarose $1,5 \% \mathrm{em}$ tampão de ácido Bórico-Tris-EDTA (TBE) e revelados com Syber Green ${ }^{\circledR}\left(0,5 \mathrm{mg} \mathrm{ml}^{-1}\right.$ - Invitrogen). Os produtos foram analisados comparativamente com marcadores de DNA de 50bp e fotografados em analisador de imagens (Alphaimager - Alpha esasy FC Software - AlphaInotech Corporation). Os dados foram analisados utilizando-se a regressão logística através do procedimento PROC LOGISTIC do software pacote estatístico SAS (SAS Inst. Inc., Cary, NC, EUA). Os diferentes tratamentos das diversas análises foram considerados como efeitos fixos. Adotou-se o nível de $5 \%$ de significância.

Em total de 130 amostras analisadas, 49,2\% (64/130) apresentaram resultados positivos para Salmonella, independente do método (MC/PCR) e do tipo de amostra (indústria e simulação de varejo). Essa alta ocorrência pode estar relacionada à contaminação dos lotes ainda nas granjas por influência das condições higiênico-sanitárias, climáticas e ambientais, ao transporte dos animais, às condições do ambiente pré-abate nos estabelecimentos industriais e ao próprio processamento industrial para obtenção das carcaças, além da metodologia analítica empregada (CARVALHO \& CORTEZ, 2008). Do total de amostras positivas (64), a PCR detectou 58 e a MC, 50.

Quanto aos resultados dos diferentes tipos de amostra analisados (indústria e varejo), obtidos por qualquer uma das técnicas empregadas (MC + PCR: Tabela 1), pode-se observar que aquelas colhidas ainda na indústria mostraram uma porcentagem superior de amostras positivas $(6,15 \%)$ para o patógeno em relação àquelas estocadas simulando as condições do varejo. Tais dados divergem dos apresentados por FLETCHER (2006), que detectou um aumento de $21,6 \%$ na positividade das amostras colhidas no varejo quando comparadas às da indústria. Essa tem sido uma tendência observada na maioria dos trabalhos, ou seja, a positividade das amostras do varejo ser sempre superior àquela detectada nas carcaças colhidas logo após a etapa de resfriamento nos chillers.

Segundo FLETCHER (2006), nesta etapa do fluxograma, as células de Salmonella presentes nas carcaças além de estarem geralmente em um pequeno número, encontram-se injuriadas, como resultado de vários processos pelos quais elas passam ao longo do abate (FLETCHER, 2006). Segundo dados relatados por este autor, em um estudo realizado pelo Serviço de Inspeção Federal norte-americano, $42 \%$ das carcaças nesta etapa apresentavam menos que 12 células de Salmonella e, em $43 \%$ das amostras examinadas, as contagens variavam de 12 a 120 células carcaça ${ }^{-1}$. Assim, a colheita das amostras logo após o chiller poderia subestimar a ocorrência de Salmonella nas carcaças, com reflexo nos resultados do PRP.

Nossos dados não reforçam esta hipótese, já que, independentemente da técnica utilizada (PCR ou metodologia convencional), as porcentagens de amostras positivas sempre foram superiores naquelas colhidas na indústria. Quando se empregou a técnica microbiológica convencional, 46,15\% das carcaças mostraram-se contaminadas na indústria e 30,77\% após a simulação do varejo, observando-se um decréscimo de $15,4 \%$ entre os dois tipos de amostra. Quando se utilizou a PCR, 50,77\% eram positivas na indústria e $38,46 \%$, no varejo, decréscimo de $12,31 \%$. Assim, podemos considerar que talvez o efeito contínuo do frio durante a estocagem das carcaças, conforme registrado por JIMENEZ et al. (2009), seja mais deletério às células de Salmonella do que as operações realizadas durante o abate e nomeadas por FLETCHER (2006). Essa diferença pode ser observada pelas duas metodologias avaliadas, sendo que a PCR foi aquela capaz de detectar o maior número de amostras positivas para o micro-organismo em ambos os casos. Esta performance superior da técnica molecular pode ser resultante de sua capacidade de detectar um baixo número de células do patógeno, conferindo-lhe alta sensibilidade. Além de estarem presentes em pequeno número, as células de Salmonella encontram-se injuriadas, não somente pela ação do frio, mas também em decorrência da presença de produtos químicos e antimicrobianos como, por exemplo, o cloro, empregado no processo de abate das aves (FLETCHER, 2006). Esta injúria muitas vezes não consegue ser revertida durante a análise microbiológica convencional, impedindo a sua detecção.

Segundo UYTTENDAELE et al. (1998), o emprego de diferentes temperaturas durante o abate das aves pode dificultar a detecção de Salmonella, quando esta se dá pela metodologia microbiológica convencional. Torna-se necessário um período maior de incubação das amostras durante a fase de enriquecimento, já que se observa uma extensão da fase lag na curva de crescimento do patógeno. No caso da PCR, embora esta influência também exista, já que a pesquisa do agente também se dá a partir dos caldos de enriquecimento empregados na metodologia convencional, ela é menor, dada a maior sensibilidade do método.

Esta maior sensibilidade da PCR pode ser ainda melhor evidenciada se cruzarmos os resultados 
Tabela 1 - Resultados positivos para Salmonella sp. em carcaças de frango analisadas por PCR e MC. Amostras colhidas na indústria e após simulação de varejo.

\begin{tabular}{lcccc}
\hline Técnica utilizada e momento avaliado & $\begin{array}{c}\text { Resultados positivos } \\
\text { Indústria }\end{array}$ & $\begin{array}{c}\text { Resultados positivos } \\
\text { Simulação varejo }\end{array}$ & $\begin{array}{c}\text { Diferença indústria e } \\
\text { Simulação varejo }\end{array}$ & $\begin{array}{l}\text { Valor de P } \\
\text { IND* (MC*) x VAREJO* (MC) }\end{array}$ \\
IND (PCR*) x VAREJO (PCR) & $46,15 \%$ & $30,77 \%$ & $15,38 \%$ & 0,07 \\
IND (PCR) x VAREJO (MC) & $50,77 \%$ & $38,46 \%$ & $12,31 \%$ & 0,12 \\
IND (MC) X VAREJO (PCR) & $50,77 \%$ & $30,77 \%$ & $20,00 \%$ & 0,02 \\
MC + PCR ** & $46,15 \%$ & $38,46 \%$ & $7,69 \%$ & 0,37 \\
\hline
\end{tabular}

*IND- Momento Indústria; VAREJO - Momento Simulação do varejo; MC- Microbiológico convencional; PCR-Reação em cadeia da polimerase.

** Porcentagem de resultados positivos independentemente da técnica utilizada.

obtidos pelas duas técnicas a partir de diferentes tipos de amostra (Tabela 1). Por exemplo, aquelas colhidas na indústria, quando analisadas pela PCR, mostraram uma positividade de $50,77 \%$, ao passo que, nas do varejo, analisadas pela $\mathrm{MC}$, a porcentagem de positivas foi de $30,77 \%$, uma diferença de $20 \%$. Ao contrário, quando as amostras na indústria foram analisadas pela MC, a positividade foi de $46,65 \%$ e as do varejo pela PCR de $38,46 \%$, sendo a diferença de apenas 7,69\%. Tais dados ratificam o desempenho superior da técnica molecular em relação à convencional.

Em resumo, os nossos dados reforçam a influência do frio na detecção de Salmonella em carcaças de frango, especialmente quando se emprega a metodologia microbiológica convencional de análise. Assim, a PCR revela-se uma ferramenta importante na pesquisa deste patógeno neste tipo de produto.

Desse modo, podemos concluir que o resfriamento das carcaças pode ser um fator limitante na detecção de Salmonella quando a pesquisa se faz pela metodologia microbiológica convencional. A PCR apresenta-se como uma alternativa rápida, de fácil execução, podendo ser especialmente útil no monitoramento dos índices de contaminação desse tipo de produto, tanto em amostras colhidas ainda na indústria como aquelas obtidas no comércio varejista.

\section{AGRADECIMENTOS}

Fundação de Amparo a Pesquisa do Estado de São Paulo (FAPESP) - PROCESSO 09/52082-5

\section{REFERÊNCIAS}

ANDREWS, W.H, et al. Salmonella. In: FOOD AND DRUG ADMINISTRATION - Bacteriological analytical manual. 8.ed. Gaithersburg: AOAC INTERNATIONAL, 1998. p.5.015.020 .
ARNOLD, T.A. et al. Impact of invA-PCR and culture detection methods on occurrence and survival of salmonella in the flesh, internal organs and lymphoid tissues of experimentally infected pigs. Journal of Veterinary Medicine series B, v.51, n.10, p.459-463, 2004. Disponível em: <http://onlinelibrary.wiley.com/ doi/10.1111/j.1439-0450. 2004.00808.x/abstract;jsessionid $=755 \mathrm{DEB} 7 \mathrm{~B} 31 \mathrm{~B}$ 3811EDAA8EF298DA066C2.d01t04>. Acesso em: 15 out. 2011. doi: 10.1111/j.1439-0450.2004.00808.x.

BRASIL. Ministério da Agricultura Pecuária e Abastecimento. Instrução Normativa n.70, de 06 de outubro de 2003. Brasília, 2003. Disponível em: <http://extranet.agricultura.gov.br/ sislegisconsulta/servlet/VisualizarAnexo?id=1855>. Acesso em: 01 set. 2007.

CARVALHO, A.C.F.B.; CORTEZ, A.L.L. Salmonella spp. em carcaças, carne mecanicamente separada, lingüiças e cortes comerciais de frango. Ciencia Rural, Santa Maria, v.25, p.14651468, 2008. Disponível em: <http://www.scielo.br/ scielo.php?pid=S0103-84782008000900023\&script=sci_arttext $>$. Acesso em: 15 out. 2011. doi: 10.1590/ S010384782008005000082 .

FLECTHER, D.L. Influence of sampling methodology on reported incidence of salmonella in poultry. Journal of AOAC International, v.89, p.512-516, 2006.

FRESCHI, C.R. et al. Comparison of DNA-extraction methods and selective enrichment broths on the detection of Salmonella Typhimurium in swine feces by polymerase chain reaction (PCR). Brazilian Journal of Microbiology, v.36, p.363367, 2005. Disponível em: <http://dx.doi.org/10.1590/S151783822005000400011>. Acesso em: 15 out. 2011 . doi: 10.1590/ S1517-83822005000400011.

GREISEN, K. et al. PCR primers and probes for the $16 \mathrm{~S}$ rRNA gene of most species of pathogenic bacteria, including bacteria found in cerebrospinal fluid. Journal of Clinical Microbiology, v.32, n.2 p.335-351, 1994. Disponível em: <http://www.ncbi.nlm.nih.gov/pmc/articles/PMC263034/pdf/ jcm00002-0075.pdf>. Acesso em: 15 out. 2011.

JIMENEZ, S.M. et al. Survival of Salmonella on refrigerated chicken carcass and subsequent transfer to cutting board. Letters of Applied Microbiology, v.48, p687-691, 2009. Disponível em: <http://onlinelibrary.wiley.com/doi/10.1111/j.1472- 
765X.2009.02596.x/full>. Acesso em: 15 out. 2011. doi: 10.1111/j.1472-765X.2009.02596.x.

MEAD, S.P. et al. Food-related illness and death in the United States. Emerging of Infectious Diseases, v.5, n.5, p.607625, 1999. Disponível em: < http://www.ncbi.nlm.nih.gov/ pmc/articles/PMC2627714/ pdf/10511517.pdf>. Acesso em: 15 out. 2011 . doi: 10.3201/eid0505.990502.

NZFSA - NEW ZEALAND FOOD SAFETY AUTHOROTY. Food safety risk profile for Salmonella species in broiler (young) chickens. Christ churchi, 2007. 30p. Disponível em: 〈http:// www.nzfsa.govt.nz>. Acesso em: 14 out. 2008.

PERSING, D.H. Polymerase chain reaction: trenches to benches. Journal of Clinical Microbiology, v.29, p.1281-1285, 1991. Disponível em: < http://www.ncbi.nlm.nih.gov/pmc/articles/ PMC270100/pdf/jcm00043-0017.pdf >. Acesso em: 15 out. 2011.

RAHN, K. et al. Amplification of an invA gene sequence of Salmonella typhimurium by polymerase chain reaction as a specific method of detection of Salmonella. Molecular and Cellular Probes, v.6, p.271-279, 1992. Disponível em: <http://www.sciencedirect.com/science/article/pii/ 089085089290002F>. Acesso em: 15 out. 2011. doi: 10.1016/ 0890-8508(92)90002-F.

SIMMONS, M. et al. Recovery of Salmonella from retail broilers by a whole-carcass enrichment procedure. Journal of Food Protection, v.66, p.446-450, 2003. Disponível em: <http://www.ingentaconnect.com/content/iafp/jfp/2003/ $\begin{array}{llllllllllllllllll}0 & 0 & 0 & 0 & 0 & 0 & 6 & 6 & / & 0 & 0 & 0 & 0 & 0 & 0 & 0 & 3 & /\end{array}$ art00015 ? token=005110 cf405847447b492b6c2 431426f5b3a5f524833757e6f4f2858592f3f3b57b40cc63eeb8ff34>. Acesso em: 15 out. 2011.

UYTTENDAELE, M. et al. Influence of cold stress on the preliminary enrichment time needed for detection of enterohemorrhagic Escherichia coli in ground beef by PCR. Applied Environment Microbiology, v.64, n.5, p.16401643, 1998. Disponível em: < http://aem.asm.org/cgi/content/ full/64/5/1640 >. Acesso em:15 out. 2011 